\title{
EFEITO DA CALDA SULFOCÁLCICA SOBRE O ÁCARO Tetranychus mexicanus (McGregor, 1950) EM CITROS
}

\author{
Daniel Júnior de Andrade', Carlos Amadeu Leite de Oliveira', Gustavo de Nóbrega Romani ${ }^{1}$, \\ Fernando Cesar Pattaro ${ }^{1}$
} 'Depto. de Fitossanidade - FCAV/UNESP - Via de acesso Prof. Paulo Donato Castellane, s/n - CEP: 14870-000,
Jaboticabal - SP.

\section{RESUMO}

Embora a calda sulfocálcica seja de uso relativamente antigo na agricultura pouco se conhece sobre sua eficiência no controle de ácaros de importância agrícola. Portanto, o objetivo deste trabalho foi avaliar o efeito da calda sulfocálcica sobre o ácaro T. mexicanus, em diferentes dosagens, por ação direta, residual e ovicida, visando sua utilização em pomares convencionais e orgânicos. Estabeleceram-se os seguintes tratamentos, para avaliar a ação direta e residual da calda sulfocálcica, expressos em $\mathrm{mL}$ ou g do produto por $100 \mathrm{~L}$ de água: calda sulfocálcica a $3.000,4.000$, e $5.000 \mathrm{~mL}$; abamectin $36 \mathrm{CE}$ a $50 \mathrm{~mL}$ em pré-mistura com $250 \mathrm{~mL}$ de óleo vegetal; enxofre 80 GD a 400 g; e testemunha. Para avaliar a ação ovicida da calda sulfocálcica foram estabelecidos os seguintes tratamentos, expressos em $\mathrm{mL}$ do produto comercial por $100 \mathrm{~L}$ de água: calda sulfocálcica a 2.000;3.000; 4.000 e $5.000 \mathrm{~mL}$; abamectin a $50 \mathrm{~mL}$ em pré-mistura com $250 \mathrm{~mL}$ de óleo vegetal e testemunha. A partir dos resultados, pode-se concluir que a calda sulfocálcica nas dosagens de $3.000 ; 4.000$ e $5.000 \mathrm{~mL}$ para $100 \mathrm{~L}$ de água é eficiente no controle do ácaro T. mexicanus, em citros, com eficácia semelhante ao abamectin + óleo vegetal, tanto por ação direta quanto por ação residual. Todas as dosagens de calda sulfocálcica testadas foram eficientes no controle de ovos de T. mexicanus, com resultados superiores a abamectin + óleo.

Palavras-chave: controle químico, sulfurado inorgânico, citros orgânico, ácaro mexicano.

\section{EFFECT OF LIME SULFUR ON Tetranychus mexicanus (McGregor, 1950) MITE ON CITRUS}

\begin{abstract}
Although the lime sulfur has a traditional use in the agriculture, little is known about its efficiency in mite pest control. Therefore this paper evaluates the effect of lime sulfur on $T$. mexicanus, testing different dosages, by direct, residual and ovicide action, aiming its use in ordinary or organic citrus orchards. To analize the direct and the residual action of lime sulfur, expressed in $\mathrm{mL}$ or $\mathrm{g}$ of the product in $100 \mathrm{~L}$ of water, the following treatments were established: lime sulfur in 3,$000 ; 4,000$; and $5,000 \mathrm{~mL}$; abamectin $36 \mathrm{CE}$ in $50 \mathrm{ml}$ premixed with $250 \mathrm{ml}$ of vegetable oil; sulfur $80 \mathrm{GD}$ in $400 \mathrm{~g}$; and control. For evaluating the action of lime sulfur on the eggs the following treatments were established, expressed in $\mathrm{ml}$ of the commercial product in 100 L of water: lime sulfur in 2,000;3,000; 4,000 and 5,000 mL; abamectin in $50 \mathrm{ml}$ pre-mixed with $250 \mathrm{ml}$ of vegetal oil and control. The results have indicated that the lime sulfur in 3,$000 ; 4,000$ and $5,000 \mathrm{~mL}$ dosages in $100 \mathrm{~L}$ of water is efficient to T. mexicanus control, on citrus, very similar to abamectin and vegetal oil, in direct and residual action. All the dosages of lime sulfur tested were efficient to control the T. mexicamus eggs, with better results than abamectin and oil.
\end{abstract}

Key-words: chemical control, inorganic sulfur, organic citrus, mexican mite. 


\section{INTRODUÇ̃̃O}

O Brasil é o maior produtor mundial de citros, com cerca de 810 mil hectares cultivados e uma produção de aproximadamente 16,4 milhões de toneladas em 2005 (Agrianual, 2006). No entanto, a produtividade média dos pomares brasileiros é considerada baixa, em grande parte devido à incidência de pragas, que são responsáveis por grande parte do custo de produção.

$\mathrm{O}$ ácaro Tetranychus mexicanus (McGregor, 1950) (Acari: Tetranychidae) foi relatado primeiramente nos Estados Unidos da América e posteriormente no México e Argentina. No Brasil foi referido por Flechtmann \& Paschoal (1967), tendo sido depois relatado em diversos outros hospedeiros, sobre os quais tece grandes quantidades de teias. A espécie tem provavelmente os citros como principal hospedeiro (Rodrigues \& Oliveira, 2005). Nessa cultura, pode acarretar intensa desfolha, prejudicando o desenvolvimento das plantas, motivo pelo qual, seu controle com acaricidas tem sido comumente realizado.

Em citros sua incidência é mais comum em mudas, em condições de viveiro. As fềmeas são esverdeadas, embora em outras plantas hospedeiras sejam avermelhadas, com manchas escuras no dorso. Medem 0,50 $\mathrm{mm}$ e se reproduzem sexuadamente ou por partenogênese arrenótoca. O periodo de incubação é de 6,5 dias e o ciclo é completado em aproximadamente 18 dias para o macho e 19,5 dias para a fêmea, à temperatura de 19 a $25^{\circ} \mathrm{C}$, sem controle de umidade (Paschoal, 1968). Os ovos são esféricos e ligeiramente amarelados, sendo sempre colocados nas teias (Rodrigues \& Oliveira, 2005).

Nas regiões citrícolas do Estado de São Paulo sua ocorrência é maior nos meses secos do ano, que corresponde ao período de inverno (Oliveira, 1993). Infesta principalmente a superfície abaxial das folhas e as depressões do fruto causando ligeira descoloração do tecido afetado, que se intensifica com o aumento populacional (Flechtmann \& Paschoal, 1967).

São várias as alternativas de controle do acarino sendo que dentre esses questionase o uso da calda sulfocálcica. Segundo Polito (2001), citado por Pattaro (2003), a calda sulfocálcica foi preparada pela primeira vez por Grison, em 1852, e sua principal utilização destinava-se ao controle preventivo de doenças fúngicas em frutíferas de clima temperado. Porém como apresenta baixa especificidade pode ser usada para outras finalidades.

Atualmente, a calda sulfocálcica é um produto utilizado na agricultura orgânica e há vários anos seu emprego tem sido mais freqüente no controle do ácaro da leprose Brevipalpus phoenicis e da falsa ferrugem Phyllocoptruta oleivora (Pattaro, 2003).

A calda sulfocálcica é um sulfurado inorgânico que possui como princípio ativo o polissulfeto de cálcio, obtido pela dissolução de enxofre em pó e cal virgem ou hidratada. Atua como fungicida, acaricida e inseticida devido às suas propriedades redutoras, tóxicas e cáusticas. Além disso, pode ser usada como adubo foliar, fornecendo principalmente cálcio e enxofre as plantas. É um dos poucos produtos químicos aceitos pelo Instituto Biodinâmico de Desenvolvimento Rural (IBD), primeira certificadora brasileira de produtos orgânicos reconhecida pela IFOAM - Intermational Federation of Organic Agriculture Movementes em 1995 (Pattaro \& Oliveira, 2005). Embora a calda sulfocálcica seja de uso relativamente antigo na agricultura pouco se conhece sobre sua eficiência no controle de ácaros de importância agrícola.

Portanto, o objetivo deste trabalho foi avaliar o efeito da calda sulfocálcica sobre o ácaro T. mexicanus, em diferentes dosagens, por ação direta, residual e ovicida, visando à sua utilização em pomares de citros 
orgânico, haja vista a carência de produtos acaricidas para tal finalidade.

\section{MATERIAL E MÉTODOS}

Os bioensaois nos quais se avaliaram a ação direta, residual e ovicida da calda sulfocálcica (Super S20: calda sulfocálcica Fertibom - concentração de $20 \%$ de enxofre e $8 \%$ de cálcio por litro de produto comercial) sobre o ácaro $T$. mexicanus foram realizados no Laboratório de Acarologia do Departamento de Fitossanidade da Faculdade de Ciências Agrárias e Veterinárias, Universidade Estadual Paulista, Campus de Jaboticabal-SP.

Criação-estoque de $T$. mexicanus: Inicialmente, foram coletadas folhas de citros altamente infestadas por $T$. mexicanus em pomares localizados na Faculdade de
Ciências Agrárias e Veterinárias, os quais, não vinham sendo pulverizados com qualquer tipo de agrotóxicos por vários meses. As folhas contendo os ácaros foram fixadas em mudas de citros com aproximadamente um ano de idade, para início da criação-estoque, e mantidas em câmara climatizada a $25 \pm 1^{\circ} \mathrm{C}$, umidade relativa de $60 \pm 5 \%$ e fotofase de 14 horas.

Bioesaio de ação direta e residual da calda sulfocálcica sobre ácaros adultos de $T$. mexicanus: $O$ delineamento experimental utilizado nos bioensaios de ação direta e residual foi o inteiramente casualizado, com seis tratamentos foram repetidos quatro vezes, sendo cada repetição composta por um disco de folha de citros de $2,5 \mathrm{~cm}$ de diâmetro, totalizando 24 discos (Tabela 1).

Tabela 1. Relação dos produtos utilizados nos bioensaios de ação direta e residual sobre adultos de T. mexicanus.

\begin{tabular}{ccc}
\hline Nome comum & Nome comercial & $\begin{array}{c}\text { Dosagens } \\
\text { mL ou g.p.c./100L }\end{array}$ \\
\hline Calda sulfocálcica & Super S20 - (Fertibom) & 3.000 \\
Calda sulfocálcica & Super S20 - (Fertibom) & 4.000 \\
Calda sulfocálcica & Super S20 - (Fertibom) & 5.000 \\
Abamectin + óleo & Kraft36 CE + Natur'l óleo & $50+250$ \\
Enxofre & Kumulus GD & 400 \\
Testemunha & - & - \\
\hline
\end{tabular}

Os discos de folha de Citrus sinensis da variedade Pêra foram obtidos através de um vazador circular de metal e colocados com a superfície abaxial voltada para cima em placas de Petri de $9 \mathrm{~cm}$ de diâmetro por $2 \mathrm{~cm}$ de altura, sobre uma camada fina de algodão hidrófilo, que foi mantido umedecido.

Para avaliar a ação direta dos produtos, foram transferidos 10 ácaros adultos de $T$. mexicanus procedentes da criação-estoque para cada disco de folha com auxílio de pincel de apenas um pêlo e utilizando-se de microscópio estereoscópico.
Para pulverização dos discos com os vários produtos utilizou-se um micropulverizador (Torre de Potter), que proporcionava uma cobertura uniforme sobre a superfície tratada, gastando-se $2 \mathrm{~mL}$ de calda por aplicação. Após as pulverizações, os discos foram mantidos em câmara climatizada às mesmas condições de temperatura, umidade relativa e luz citadas anteriormente.

Uma vez avaliado a ação direta dos produtos sobre o acarino 24,48 e 72 horas após a aplicação, retiraram-se os ácaros mortos, vivos e retidos na camada de algodão, aproveitando-se os mesmos discos 
foliares tratados para em seguida transferirse 10 ácaros adultos de T. mexicanus, ou seja, 72 horas após a aplicação, para avaliação da eficiência residual dos produto. As contagens de ácaros, para avaliar a ação residual, foram realizadas a intervalos de tempo semelhantes aos adotados para a avaliação da ação direta dos produtos.

Os dados relativos às contagens de ácaros foram transformados em $\ln (x+5)$, com o objetivo de normalizar os dados a serem analisados pelo teste F. As médias foram comparadas pelo teste de Tukey, 5\% de probabilidade. A redução real ou eficiência foi calculada pela fórmula de Abbott (1925), tomando-se por base a população de ácaros vivos de cada tratamento e transformados em porcentagem de sobrevivência.

Bioesaio de ação ovicida da calda sulfocálcica: $O$ delineamento experimental utilizado no bioensaio de ação ovicida foi o inteiramente casualizado, com seis tratamentos, repetidos cinco vezes, sendo cada repetição representada por um disco de folha de citros de $2,5 \mathrm{~cm}$ de diâmetro, totalizando 30 discos (Tabela 2). Esses discos foliares foram postos em placas de Petri contendo algodão hidrófilo, também mantidos umedecidos, para os quais foram transferidas 10 fêmeas do T. mexicanus para efetuarem postura.

Tabela 2. Relação dos produtos utilizados no bioensaio de ação ovicida dos produtos sobre ovos de T.mexicanus.

\begin{tabular}{ccc}
\hline \multirow{2}{*}{ Nome comum } & Nome comercial & Dosagens \\
\cline { 3 - 3 } & & mL ou g. p.c./100L \\
\hline Calda sulfocálcica & Super S20 - (Fertibom) & 3.000 \\
Calda sulfocálcica & Super S20 - (Fertibom) & 4.000 \\
Calda sulfocálcica & Super S20 - (Fertibom) & 5.000 \\
Calda sulfocálcica & Super S20 - (Fertibom) & $50+250$ \\
Abamectin + óleo & Kraft36 CE + Natur'l óleo & 400 \\
Testemunha & - & - \\
\hline
\end{tabular}

Decorridos três dias após a transferência, as fêmeas foram eliminadas, deixando-se em média 25 ovos por tratamento. A aplicação dos produtos foi realizada de modo semelhante ao bioensaio anterior, pulverizando-se os discos foliares contendo os ovos de T. mexicanus. Após a pulverização, os discos foram transferidos para câmara climatizada e mantidos às mesmas condições de temperatura, umidade relativa e fotofase citadas anteriormente.

larvas eclodidas fuantificações do número de diariamente, após a aplicação dos produtos. A eficiência ovicida foi calculada pela fórmula de Abbott (1925), tomando-se por base a população de larvas eclodidas.

\section{RESULTADOS E DISCUSSÃO}

Ação direta da calda sulfocálcica sobre adultos: Foi constatado que 24, 48 e 72 horas após a aplicação dos produtos sobre os ácaros adultos de $T$. mexicanus, todos os tratamentos diferiram estatisticamente da testemunha, evidenciando que a calda sulfocálcica e abamectin + óleo, nas dosagens testadas, apresentaram excelente ação de choque sobre adultos de $T$. mexicanus, com percentuais de controle acima de 94,7\% ( Tabela 3 e Figura 1).

Observaram-se diferenças significativas entre os tratamentos, calda sulfocálcica e abamectin + óleo, e enxofre. Já 24 horas após a aplicação, a eficiência foi elevada. $\mathrm{O}$ tratamento com enxofre mostrou- 
se inferior aos demais, com percentuais de controle que variaram de 62,5 a $69,4 \%$, estatisticamente diferente da testemunha (Tabela 3 e Figura 1). Esses resultados concordam com Pattaro et al. (2002) que constataram alta eficiência da calda sulfocálcica (acima de 86\%) nas dosagens de 3.000 e $4.000 \mathrm{~mL}$ para 100 litros de água sobre $T$. mexicanus em mudas cítricas. Pattaro (2003) avaliou a ação direta da calda sulfocálcica sobre Brevipalpus phoenicis e também obteve eficiência satisfatória, até mesmo com baixa concentração do produto (1.000 mL/100 L de água).

Ação residual da calda sulfocálcica sobre adultos: $\mathrm{Na}$ avaliação realizada 24 horas após a transferência dos ácaros, todas as dosagens de calda sulfocálcica testadas apresentaram baixa eficiência residual sobre T. mexicanus, que não ultrapassaram a $18,4 \%$ não diferindo estatisticamente da testemunha (Tabela 3 e Figura 2).

A calda sulfocálcica na dose de 5.000 $\mathrm{mL}$ para 100 litros de água proporcionou uma eficiência de controle semelhante ao tratamento com enxofre. Diferentemente dos resultados deste trabalho, Oliveira et al. (2002) verificaram que a calda sulfocálcica apresenta elevada eficiência residual sobre o ácaro da falsa ferrugem $P$. oleivora. Já, Pattaro (2003) observou que a calda sulfocálcica em dosagens de até 4.000 $\mathrm{mL} / 100 \mathrm{~L}$ de água apresenta baixa ação residual sobre adultos de $B$. phoenicis.

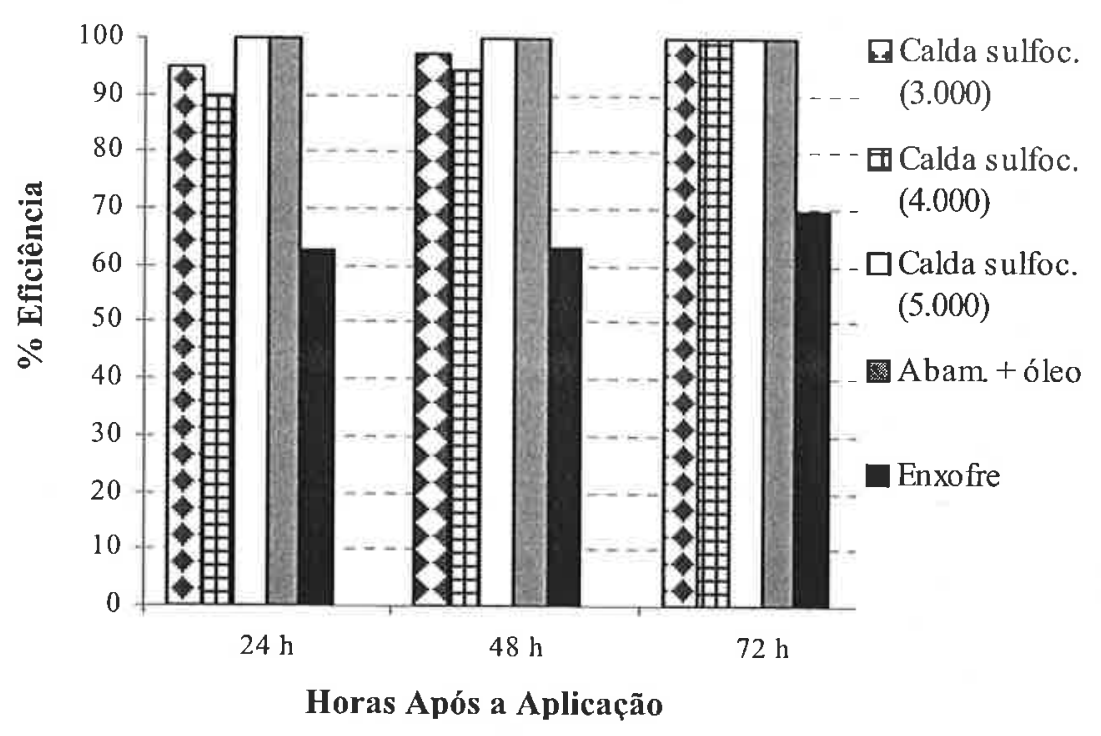

Figura 1: Porcentagem de eficiência dos produtos no controle de $T$. mexicanus por ação direta, nas avaliações realizadas 24,48 e 72 horas após a aplicação dos produtos 


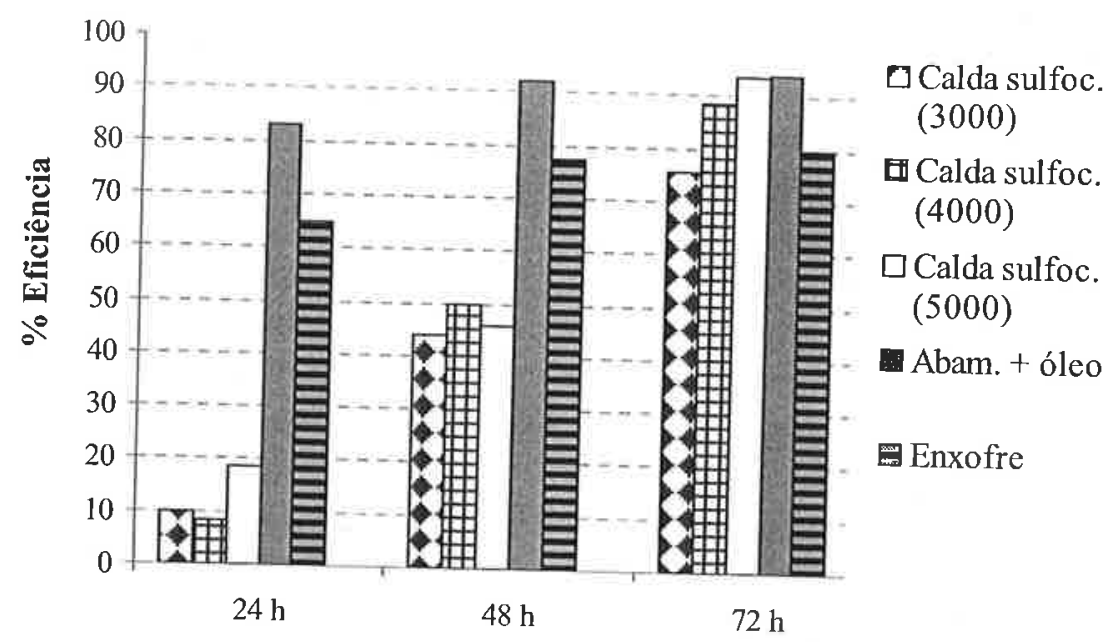

Horas Após a transferência

Figura 2: Porcentagem de eficiência dos produtos no controle de $T$. mexicanus por ação residual, nas avaliações realizadas 24,48 e 72 horas após a transferência dos ácaros.

Decorridas 48 e 72 horas da transferência dos ácaros, notou-se um aumento considerável da eficiência dos produtos, principalmente em relação aos tratamentos com a calda sufocálcica. Todos os tratamentos mostraram eficiências semelhantes 72 horas após a transferência dos ácaros, porém diferentes da testemunha
(Tabela 3). Os percentuais de controle dos produtos por ação residual, foram acima de $75 \%$ para calda sulfocálcica e acima de $90 \%$ para o abamectin + óleo e enxofre (Figura 2). Esses resultados evidenciam que a eficácia dos produtos é aumentada a medida aumenta o período de exposição do acarino ao resíduo dos produtos.

Tabela 3. Número médio de ácaros $T$. mexicanus vivos relativos às avaliações realizadas $24,48 \mathrm{e}$ 72 horas após a aplicação no bioensaio de ação direta e após a transferência dos ácaros no bioensaio de ação residual.

\begin{tabular}{|c|c|c|c|c|c|c|c|}
\hline \multirow{3}{*}{ Tratamentos } & \multicolumn{4}{|c|}{ Ação direta } & \multirow{2}{*}{\multicolumn{3}{|c|}{$\begin{array}{c}\text { Ação residual } \\
\text { Horas após } \\
\text { a transferência }\end{array}$}} \\
\hline & \multicolumn{2}{|l|}{ Dosagens } & \multicolumn{2}{|c|}{$\begin{array}{l}\text { Horas após } \\
\text { a aplicação }\end{array}$} & & & \\
\hline & $\begin{array}{l}\mathrm{mL} \text { ou g } \\
\text { p.c./100L } \\
\end{array}$ & 24 & 48 & 72 & 24 & 48 & 72 \\
\hline Calda sulf. & 3.000 & $0,5 \quad \mathrm{c}$ & $0,2 \quad \mathrm{c}$ & $0,0 \quad \mathrm{c}$ & $9,0 \mathrm{a}$ & $5,6 a$ & $2,4 \quad b$ \\
\hline Calda sulf. & 4.000 & $1,0 \quad \mathrm{c}$ & $0,5 \quad \mathrm{c}$ & $0,0 \quad \mathrm{c}$ & $9,2 \mathrm{a}$ & $5,0 \mathrm{abc}$ & $1,2 \mathrm{~b}$ \\
\hline Calda sulf. & 5.000 & $0,0 \quad \mathrm{c}$ & $0,0 \quad \mathrm{c}$ & $0,0 \quad \mathrm{c}$ & $8,2 \mathrm{ab}$ & $5,4 \mathrm{ab}$ & $0,6 \mathrm{~b}$ \\
\hline Abam. + óleo & $50+250$ & $0,0 \quad \mathrm{c}$ & $0,0 \quad \mathrm{c}$ & $0,0 \quad \mathrm{c}$ & $1,7 \quad \mathrm{c}$ & $0,8 \quad \mathrm{c}$ & $0,6 \quad b$ \\
\hline Enxofre & 400 & $3,8 \mathrm{~b}$ & $3,5 \mathrm{~b}$ & $2,8 \mathrm{~b}$ & $3,5 \mathrm{bc}$ & $2,3 \mathrm{bc}$ & $2,0 \quad \mathrm{~b}$ \\
\hline Testemunha & - & $10,0 \mathrm{a}$ & $9,5 \mathrm{a}$ & $9,0 \mathrm{a}$ & $10,0 \mathrm{a}$ & $10,0 \mathrm{a}$ & $10,0 \mathrm{a}$ \\
\hline TESTE $\mathrm{F}$ & & $63 * *$ & $119,53 * *$ & $103,65 * *$ & $8,70^{* *}$ & $9,71 * *$ & $10,21 * *$ \\
\hline C.V. $\%$ & & 5,7 & 4,1 & 4,5 & 9,9 & 9,8 & 9,8 \\
\hline
\end{tabular}

Media seguida por letras iguais na mesma coluna não diferem entre si pelo teste de Tukey a $5 \%$ de probalidade. Para a comparação das medias, os dados originais foram transformados em $\ln (\mathrm{X}+5)$.

** Significativo pelo teste $\mathrm{F}$ a $5 \%$ de probabilidade. 
Comparando a eficácia dos produtos por ação direta em confronto com a ação residual, verifica-se, como era de se esperar, que a ação direta dos produtos sobre $T$. mexicanus foi mais rápida que a ação residual, exceto em relação ao enxofre que apresentou percentuais semelhantes (Figuras 1 e 2).

Há de se ressaltar que os produtos que agem ao nível de respiração celular podem apresentar, dependendo da espécie de ácaro, resistência cruzada com outros que ajam no mesmo nicho. Omoto (2005) constatou que $B$. phoenicis apresenta resistência cruzada entre propargite $\mathrm{e}$ enxofre, e verificou que ácaros resistentes a propargite apresentaram a razão de resistência superior a 111 vezes, para o enxofre e 4,6 vezes para a calda sulfocálcica. Dada a possibilidade de ocorrer resistência cruzada entre esses produtos, recomenda-se a não utilização desses produtos em aplicações sucessivas para o controle de $T$. mexicanus, uma vez que para $B$. phoenicis essa ocorrência já foi comprovada.

Ação ovicida da calda sulfocálcica: A partir dos dados apresentados na tabela 4, observa-se que, até aos 3 dias após a aplicação dos produtos, por não ter completado o período embrionário na testemunha, não houve diferenças estatísticas, isso se deve à não eclosão das larvas. Do quarto dia em diante, os tratamentos diferiram da testemunha, mas não entre si, com destaque para o tratamento com calda sulfocálcica a $5.000 \mathrm{~mL} / 100 \mathrm{~L}$ de água que apresentou $100 \%$ de ação ovicida até o oitavo dia após a aplicação dos produtos. Os resultados obtidos discordam de Pattaro (2003) que verificou baixa eficiência da calda sulfocálcica sobre ovos de $B$. phoenicis, cerca de $36,4 \%$ de eficiência na dosagem de $4000 \mathrm{~mL}$ do produto para $100 \mathrm{~L}$ de água. No entanto, o autor verificou que após a eclosão das larvas do ácaro $B$. phoenicis, o contato dessas com o resíduo da calda sulfocálcica resultaram em altos índices de mortalidade, obtendo, portanto, alta eficiência larvicida da calda.

$\mathrm{Na}$ avaliação realizada 8 dias após a aplicação, verifícou-se que os tratamentos com calda sulfocálcica continuaram diferindo estatisticamente da testemunha e apresentando as mais elevadas reduções, com percentuais de controle que variaram de 97,1 a $100 \%$, para os tratamentos com calda a $2.000 \mathrm{~mL} / 2000 \mathrm{~mL}$ de água e 5000 $\mathrm{mL} / 2000 \mathrm{~L}$ de água, respectivamente (Tabela 4 e Figura 3). O tratamento com abamectin + óleo vegetal apresentou a menor porcentagem de eficiência ovicida $(80,8 \%)$, porém, não diferente estatisticamente dos tratamentos que utilizaram calda sulfocálcica.

Tabelạ 4: Número médio de larvas eclodidas de $T$. mexicanus 1, 2, 3, 4, 6, 7 e 8 dias, após a pulverização dos produtos sobre os ovos.

\begin{tabular}{|c|c|c|c|c|c|c|c|c|}
\hline \multirow{2}{*}{ Tratamentos } & \multicolumn{3}{|l|}{ Dosagens } & \multicolumn{3}{|c|}{ Dias após a aplicação } & \multirow[b]{2}{*}{ 7DAA } & \multirow[b]{2}{*}{ 8DAA } \\
\hline & $\begin{array}{c}\mathrm{mL} \\
\text { p.c. } / 100 \mathrm{~L}\end{array}$ & 1DAA & 2DAA & 3DAA & 4DAA & 6DAA & & \\
\hline Calda sulf. & 2.000 & $0,0 \mathrm{a}$ & 0 &, $0 \mathrm{a}$ & $0,0 \quad 0$ & $0,4 \mathrm{~b}$ & $0,6 \mathrm{~b}$ & $0,6 \mathrm{~b}$ \\
\hline Calda sulf. & 3.000 & $0,0 \mathrm{a}$ & $0,0 \mathrm{a}$ & $0,0 \mathrm{a}$ & $0,0 \mathrm{~b}$ & $0,2 \mathrm{~b}$ & $0,2 \mathrm{~b}$ & $0,2 \mathrm{~b}$ \\
\hline Calda sulf. & 4.000 & $0,0 \mathrm{a}$ & $0,0 \mathrm{a}$ & $0,0 \mathrm{a}$ & $0,2 \mathrm{~b}$ & $0,2 \mathrm{~b}$ & $0,2 \mathrm{~b}$ & $0,2 \mathrm{~b}$ \\
\hline Calda sulf. & 5.000 & $0,0 \mathrm{a}$ & $0,0 \mathrm{a}$ & $0,0 \mathrm{a}$ & $0,0 \mathrm{~b}$ & $0,0 \mathrm{~b}$ & $0,0 \mathrm{~b}$ & $0,0 \mathrm{~b}$ \\
\hline Abam. + óleo & $50+250$ & $0,0 \mathrm{a}$ & $0,0 \mathrm{a}$ & $0,0 \mathrm{a}$ & $1,2 \mathrm{~b}$ & $2,4 \mathrm{~b}$ & $3,8 \mathrm{~b}$ & $3,8 \mathrm{~b}$ \\
\hline Testemunha & - & $0,0 \mathrm{a}$ & $0,0 \mathrm{a}$ & $0,6 \mathrm{a}$ & $6,6 a$ & $19,0 \mathrm{a}$ & $22,6 \mathrm{a}$ & $22,6 \mathrm{a}$ \\
\hline
\end{tabular}


A mortalidade acarretada por produtos a base de enxofre como a calda sulfocálcica, ocorre pela ação fumigante através da penetração do enxofre nas vias respiratórias dos ácaros, ocasionando a desidrogenação da célula (Corbett et al, 1984; Kadir \& Knowles, 1991). O enxofre interfere no transporte de elétrons na mitocôndria. O mesmo se admite em relação ao ácaro na fase de ovo, uma vez que as trocas gasosas do embrião com o exterior ocorre através do córion o que possibilita os processos fisiológicos ligados à respiração celular.

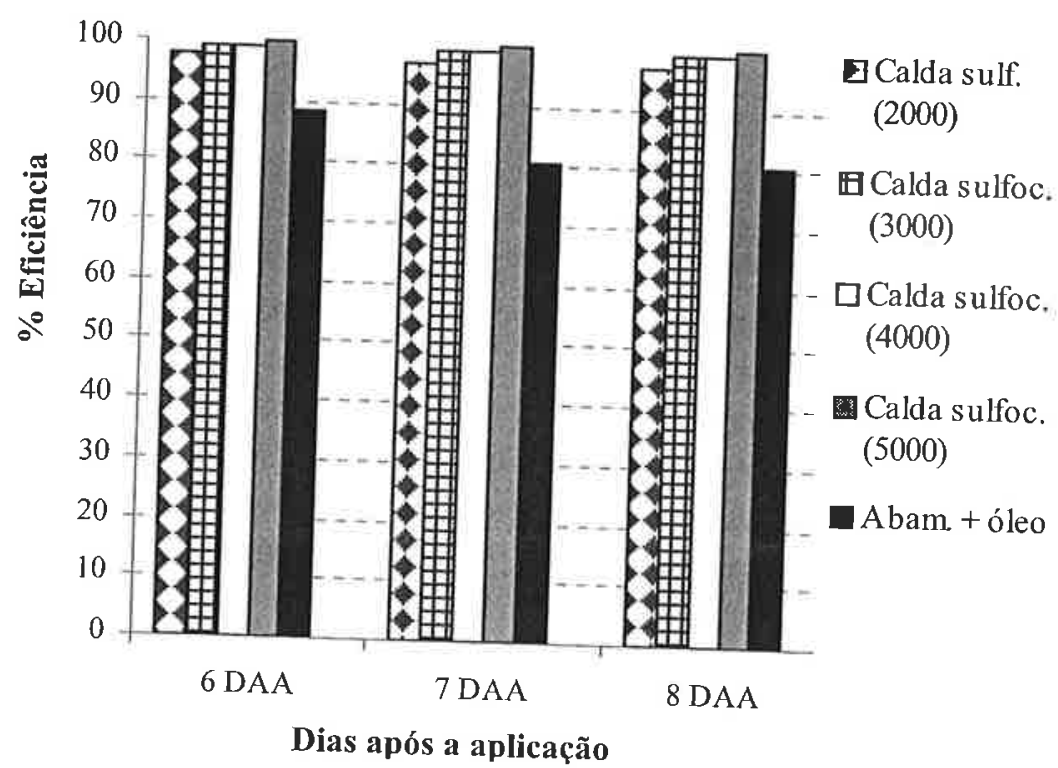

Figura 3: Porcentagem de eficiência dos produtos no controle de ovos de $T$. mexicanus por ação ovicida nas avaliações realizadas 6,7 e 8 dias após a aplicação dos produtos.

\section{CONCLUSÕES}

A calda sulfocálcica nas dosagens de $3.000,4.000$ e $5.000 \mathrm{~mL}$ por $100 \mathrm{~L}$ de água é eficiente no controle do ácaro $T$. mexicanus, em citros, com eficácia semelhante ao abamectin + óleo, tanto por ação direta quanto por ação residual.

Todas as dosagens de calda sulfocálcica testadas foram eficientes no controle de ovos de $T$. mexicanus, obtendo resultados superiores ao abamectin + óleo.

A eficácia da calda sulfocálcica sobre ovos de $T$. mexicanus pode assegurar um controle mais prolongado do ácaro em plantas de citros.

\section{REFERÊNCIAS BIBLIOGRÁFICAS}

ABBOTT, W.S. 1925. A method of computing the effectiveness of an insecticide. Journal of Economic Entomology, v. 18, n. 3, p. 265-267.

AGRIANUAL: anuária da agricultura brasileira. 11ed. São Paulo: p.257270, 2006.

ANDREI, D. 1999. Compêndio de defensivos agrícolas: guia prático de produtos fitossanitários para uso agrícola. São Paulo: Organização Andrei Editora, 672p.

CORBETT, J.R.; WRIGHT, K.; BAILLIE, A.C. 1984. The biochemical mode of action of pesticides. London. Academic Press, 382p. 
FLECHTMANN, C.H.W.; PASCHOAL, A.D. 1967. Os ácaros dos citros. O solo, v.2, p.53-56.

KADIR, H.A.; KNOWLES, C.O. 1991. Inhibition of HIP depliosphorylation by acaricides with emphases on the antiATPase atevity of the carbodiimuide metabolite of diafenthiuron. Journal of Economic Entomology, v.84, n.3, p.801-805.

OLIVEIRA, C.A.L. de. 1993.Ácaros dos citros. BASF, 18p. (Boletim Técnico).

OLIVEIRA, M.L.; PATTARO, F.C.; OLIVEIRA, C.A.L. de. Influência do resíduo de calda sulfocálcica na eficiência do Vertimec 18 CE no controle de Phyllocoptruta oleivora, em citros. In: CONGRESSO BRASILEIRO DE ENTOMOLOGIA, 19., 2002, Manaus, p.252. (Resumos).

OMOTO, C. Bases para um programa de manejo da resistência de Brevipalus phoenicis (Geijskes, 1939) (acari: Tenuipalpidae) a acaricidas em pomares de citros. 2005. 156p. Texto sistematizado (Livre-docência) - Escola Superior de Agricultura Luiz de Queiroz, Universidade de São Paulo, PiracicabaSP.
PASCHOAL, A.D. 1968. Sobre a biologia do ácaro Tetranychus mexicanus (Acarina:Tetranychidae). O Solo, v.1, p.67-70.

PATTARO, F.C. Calda sulfocálcica no agrossistema citrícola. 2003. 73p.

Dissertação (Mestrado em Agronomia) Faculdade de Ciências Agrárias e Veterinárias, Universidade Estadual Paulista, Jaboticabal-SP.

PATTARO, F.C.; BUFALINO, S.B.; OLIVEIRA, C.A.L. de. Eficiência da calda sulfocálcica sobre Tetranychus mexicanus (Mcgregor, 1950), em mudas de citros, em casa de vegetação. In: CONGRESSO BRASILEIRO DE ENTOMOLOGIA, 19., 2002, Manaus, p.252.(Resumos).

PATTARO, F.C.; OLIVEIRA, C.A.L.de. 2005. Calda sulfocálcica: aplicações e implicações. Revista Campo e Negócios, São Paulo, n.28, p.58-61.

RODRIGUES, J.C.V.; OLIVEIRA, C.A.L.de. 2005. Ácaros Fitófagos dos citros. In: MATTOS JUNIOR, D. de; NEGRI, J. D. de; PIO, R. M.; POMPEU JUNIOR, J. Citros. Campinas: Instituto Agronômico e Fundag. p.689-727. 